\title{
A High Gain Dual Notch Compact UWB Antenna with Minimal Dispersion for Ground Penetrating Radar Application
}

\author{
Surajit KUNDU ${ }^{1}$, Ayan CHATTERJEE ${ }^{1}$, Sanjay Kumar JANA ${ }^{1}$, Susanta Kumar PARUI ${ }^{2}$ \\ ${ }^{1}$ Dept. of Electronics and Communication Engineering, National Institute of Technology Sikkim \\ Ravangla-737139, Sikkim, India \\ ${ }^{2}$ Dept. of Electronics \& Tele-Comm. Engineering, Indian Institute of Engineering Science \& Technology, Shibpur \\ Howrah-711103, West Bengal, India
}

surajit.kundu@nitsikkim.ac.in, ayanmrinal26@gmail.com, skjiit@gmail.com, arkapv@yahoo.com

Submitted March 15, 2018 / Accepted September 29, 2018

\begin{abstract}
A compact $\left(27.5 \times 16.5 \times 0.8 \mathrm{~mm}^{3}\right)$ co-planar waveguide fed printed ultra-wideband antenna operating in the impedance band of $1.75-10.3 \mathrm{GHz}$ with two wide frequency notch bands at 2.2-3.9 GHz and 5.1-6 GHz, is introduced. Dual notch is achieved by inserting U-slot on the radiator and with inverted patch shaped downscaled parasitic load at the opposite end of feed line. Maximum antenna gain augmentation by about $5 \mathrm{dBi}$ is achieved without changing the bandwidth, by incorporating a dual layer reflective frequency selective surface (FSS) of dimension $33 \times 33 \times 1.6 \mathrm{~mm}^{3}$ below the antenna. The antennaFSS composite structure exhibits maximum radiation in the broadside direction with a peak gain of $9 \mathrm{dBi}$ and an average radiation efficiency of more than $80 \%$ in the operating band. Antenna transfer function and group delay are experimentally studied in ground coupling mode of ground penetrating radar (GPR). Linear magnitude response of transfer function and consistent, flat group delay are achieved, that ensure minimal antenna dispersion and its ability for GPR application.
\end{abstract}

\section{Keywords}

UWB antenna, frequency selective surface (FSS), ground penetrating radar, high gain, and notch.

\section{Introduction}

Ground penetrating radar (GPR) is a very useful sub surface scanning tool for a wide range of applications that include ice-snow-soil mapping and surveying, detecting faults, cracks in civil constructions, identifying buried landmines, police investigation and forensic works, disaster management etc. [1]. Low frequency broadband antenna that operates below $900 \mathrm{MHz}$ is conventionally used in GPR but limited bandwidth of such antennas reduces GPR resolution [2]. Moreover relatively larger antenna dimension affects GPR portability. Compact Ultra-wide band
(UWB) antenna that has a wide bandwidth, covering the unlicensed UWB band of 3.1-10.6 GHz, can be a useful candidate for sub surface GPR application [3]. However penetration depth of conventional GPR antenna degrades at high frequency due to higher soil attenuation with increasing frequency [1]. Higher gain in the direction of broadside radiation from a GPR antenna can improve the penetration depth of the radiated electromagnetic wave by tackling the higher soil attenuation. Achieving minimum dispersion is also an important requirement for GPR antenna. Higher dispersion indicates shift in antenna phase center with varying frequency, and is needed to be reduced. Apart from radiation improvement and achieving minimal dispersion, another GPR antenna design consideration is to avoid the possibility of interference from co-existing wireless technologies. Creation of multiple frequency notch bands is a possible solution for interference avoidance. Incorporating slots on antenna patch, ground plane [4-6] and addition of parasitic loads that act as resonator [7], [8] are conventional methods of notch band creation. Combination of such different methods is useful for the creation of multiple notch bands [9], [10]. Circular disk monopole antenna is one of the popular and conventional radiator shape that is widely used in UWB applications [11-13], however relatively larger dimension and lower gain restrict its use in GPR. UWB antennas such as horn, Vivaldi, bowtie and frequency independent antennas are popular entrant for GPR application [14-17]. However non-planar profile of horn antenna [14], bulky size of Vivaldi antenna [15], [16], lower gain of bowtie antenna [17] and high dispersion of frequency independent antenna [1] limit their uses in GPR.

Enhancing the broadside radiation of omni-directional or bi-directional antennas over such a wide bandwidth is a challenging job, and a possible solution is to integrate periodic structures with the antenna [18-23]. Metallic reflectors are avoided as they operate over a limited bandwidth due to nonlinear reflection phase. Frequency selective surfaces (FSS) are being extensively used either as a superstrate above the antenna [19], [22] or as a substrate 
below the antenna [18], [21] to enhance the antenna gain in a specific direction over a specific bandwidth [20] and in multiple bands [21]. However reflection phase of FSS plays an important role in this regard. Various experimental studies of UWB antenna for air coupled GPR application are considered in recent years [24], [25] whereas study in the ground coupling GPR mode also demand extensive research attention [26], [27].

A balloon shaped dual notched UWB antenna is proposed in this paper. An U-shaped slot is embedded on the patch and an inverted patch shaped resonator is embedded at the back side, in order to achieve stop bands that can eliminate possible interferences from the co-existing ISM bands (2.4-2.5 and 5.725-5.875 GHz), IEEE 802.16 WiMAX (2.5-2.7, 3.3-3.7 and 5.25-5.825 GHz), IEEE 802.11a WLAN (5.15-5.35 and 5.725-5.825 GHz), HIPERLAN/2 (5.15-5.35 and 5.47-5.725 GHz), and IEEE 802.11p DSRC (5.85-5.925 GHz). The antenna is backed by a reflective type dual-layer FSS with $3 \times 3$ array of unit cells. The proposed antenna with the FSS layers is tested in close proximity to sand to identify its working ability for GPR applications.

\section{Design and Analysis of the Antenna and FSS}

This section describes the design method of the printed monopole antenna and the FSS layers which can be used as a substrate below the antenna.

\subsection{UWB Monopole Antenna}

One major criteria of UWB antenna is achieving compactness without affecting its performance in the operational band. Intending to do so, a new balloon shaped antenna of dimension $27.5 \times 16.5 \times 0.8 \mathrm{~mm}^{3}$ is developed from the conventional circular disk monopole (CDM) antenna. The surface current is extremely concentrated along the peripherals of CDM antenna as can be found in the previous research works [11-13]. This phenomena motivate to develop the balloon shaped patch by considering the intersection of three circular disks of equal dimension marked as A, B and C as shown in Fig. 1(e). The design was initiated by taking the radius of three circular disks: $R \approx \lambda_{\mathrm{L}} / 10 \mathrm{~mm}$ where $\lambda_{\mathrm{L}}$ corresponds to lower band-edge frequency of UWB that is $3.1 \mathrm{GHz}$. A parametric design was simulated in CST MWS [28]. The resultant patch length and width became $67.5 \%$ and $50 \%$ of the diameter of conventional CDM respectively which suggests a decrease of $32.5 \%$ in length and $50 \%$ in maximum width of the balloon shaped radiator compared to circular patch. The proposed antenna has a dimension of $0.28 \lambda_{\mathrm{L}} \times 0.17 \lambda_{\mathrm{L}} \times 0.01 \lambda_{\mathrm{L}}$ that makes it electrically small. The bended ground plane and the curvature of patch close to ground plane can realize additional path for current flow that result multi-resonance modes at upper frequencies and therefore enhance the impedance band significantly. Two transitions are included in antenna feed that enhance antenna bandwidth [12]. Desired

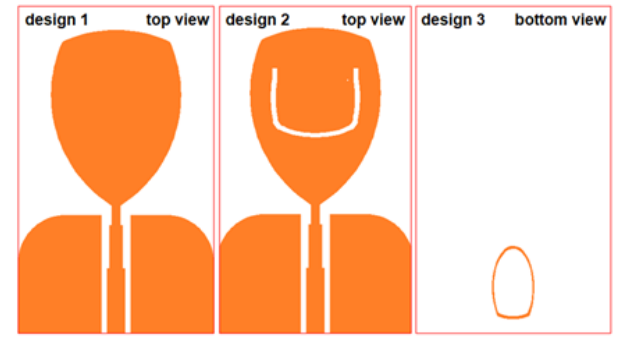

(a)

(b)

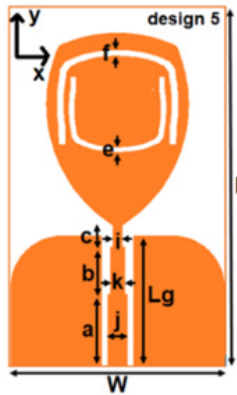

(d)

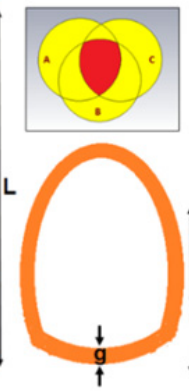

(e)

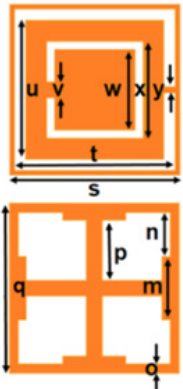

(f)
Fig. 1. Schematic view of the antenna design steps: (a) reference balloon shaped antenna, (b) antenna with U-shaped slot, (c) antenna with parasitic load, (d) the proposed dual notched antenna, (e) formation of patch and load at the bottom of antenna, and (f) unit cells of FSS.

frequency notch creation in this small antenna is a challenging task as the total length of the slot is limited. Curved shape slots are popular choice to achieve the notch band [29]. As shown in Fig. 1(b), the U shaped slot is embedded on balloon shaped patch to achieve WLAN frequency notch. The overall length of the slot and the distance between the outer and inner layer of the slot are key parameters to realize the wanted frequency stop band. The equivalent $L C$ components of $U$ slot can perform the desired band stop filtering. Considering the notch center frequency $f_{\mathrm{n}}$ at $5.5 \mathrm{GHz}$ for frequency stop band of $5-6 \mathrm{GHz}$, U-shaped slot dimensions are evaluated using:

$$
f_{\mathrm{n}}=\frac{c}{\left(l_{\mathrm{i}}+l_{\mathrm{o}}+2 e\right) \sqrt{\varepsilon_{\mathrm{e}}}}
$$

where $\varepsilon_{\mathrm{e}}=\left(\varepsilon_{\mathrm{r}}+1\right) / 2$. Here FR4 is used as a substrate with relative permittivity $\varepsilon_{\mathrm{r}}$ of 4.4 . The $U$ shaped slot has the inner length $l_{\mathrm{i}}$ of $15.6 \mathrm{~mm}$, the outer length $l_{\mathrm{o}}$ of $16.9 \mathrm{~mm}$ and the gap between the two lengths $e$ of $0.36 \mathrm{~mm}$.

Another stop band from $2.2-3.8 \mathrm{GHz}$, centered at $3 \mathrm{GHz}$ is achieved by incorporating an inverted radiator shaped parasitic load at the opposite end of the feed line. The parasitic load acting as a resonator can be designed using:

$$
f_{\mathrm{n}}=\frac{c}{4\left(\frac{T}{2}-2 g\right) \sqrt{\varepsilon_{\mathrm{e}}}} .
$$

Here $T$ denotes the total peripheral length of the resonator. Considering $f_{\mathrm{n}}$ as $3 \mathrm{GHz}$ the calculated value of $T$ and $g$ became 31.7 and $0.3 \mathrm{~mm}$ respectively. Parametric study in 
CST results in $T$ value of $30.9 \mathrm{~mm}$ and $g$ value of $0.3 \mathrm{~mm}$. Intending to improve the antenna operating bandwidth, an inverted $U$ shaped slot is also added on the radiating patch to introduce additional capacitive loading. Addition of $U$ and inverted $U$ slots improve the current path length in the balloon shaped radiator and thus compactness is achieved.

The design schematic of different stages of dual notched antenna and corresponding simulated VSWR using CST microwave studio simulator are shown in Fig. 1 and Fig. 2 respectively. Design 1 indicates the reference balloon shaped antenna. The reference antenna has a wide impedance band from 2.2 to more than $10 \mathrm{GHz}$ as can be seen in Fig. 2. The antenna with the U shaped slot, mentioned as design 2, can provide a notch band of $5-5.85 \mathrm{GHz}$ in the pass band from 4.1 to more than $10 \mathrm{GHz}$. Design 3 refers the antenna added with downscaled inverted patch shaped parasitic load at the bottom of substrate, behind the feed. This design can provide a single notch band of 2.2-4 GHz. The antenna with both the notch structures, i.e. the U-shaped slot and the parasitic load, which is stated as design 4 can provide dual notches of $2.2-4$ and $5-5.85 \mathrm{GHz}$ in the pass band from 1.9 to $10.3 \mathrm{GHz}$. The final design of the proposed dual notched antenna (design 5) can provide dual frequency stop bands at $2.2-4$ and $5-6.1 \mathrm{GHz}$ in the pass band from 1.6 to $10.56 \mathrm{GHz}$. The improvement in impedance band profile is achieved by embedding the inverse U-shaped slot on the balloon shaped patch.

Optimal values of the design parameters of the proposed dual notched antenna are specified in Tab. 1. As can be observed in Fig. 4, the final design of the reference antenna and the dual notched antenna are fabricated on FR4 epoxy substrate that has thickness of $0.8 \mathrm{~mm}$.

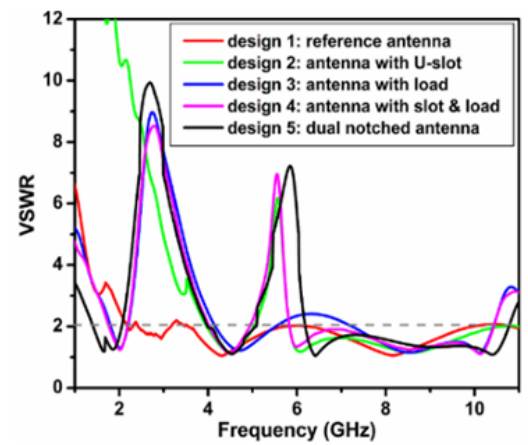

Fig. 2. Simulated VSWR plot of all antenna design variations using CST.

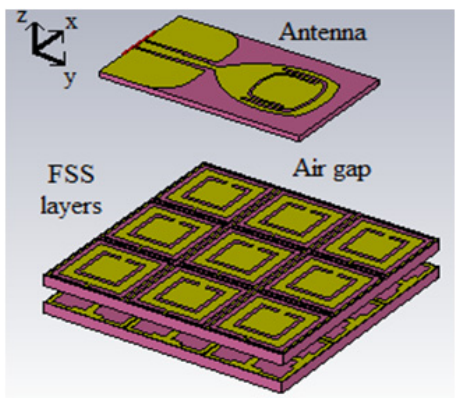

Fig. 3. Three dimensional view of the antenna with FSS layers, designed in CST MWS simulator.

\subsection{Design Principle of FSS Layers}

A dual layer reflective type FSS is designed for the purpose of enhancing the antenna radiation in the broadside direction over the UWB band. Each layer has an overall dimension of $33 \times 33 \times 1.6 \mathrm{~mm}^{3}$, and the FSS is kept at an optimal distance of $27 \mathrm{~mm}$ below the antenna as shown in Fig. 3.

The FSS layers are formed using $3 \times 3$ array of square patch shaped unit cells. As shown in Fig. 1(f), the unit cell of the upper layer is formed by embedding two split ring resonator (SRR) shaped slots in a square patch, in a con-

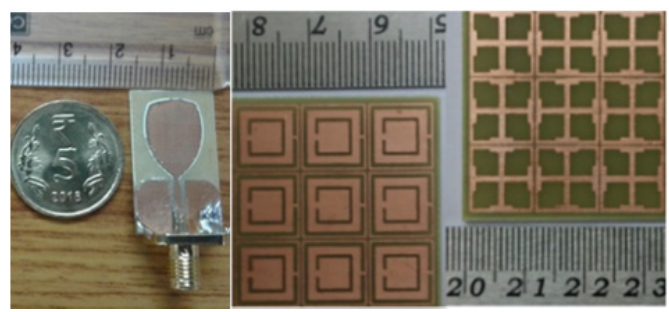

(a)

(b)

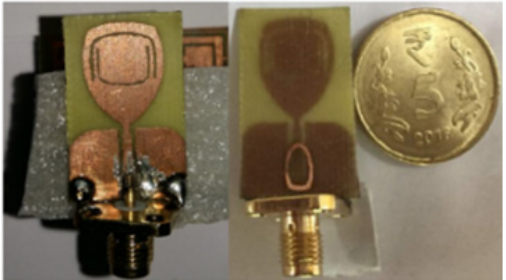

(c)

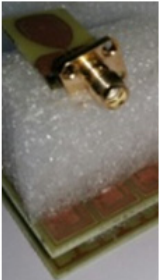

(d)
Fig. 4. Fabricated prototypes of (a) reference antenna, (b) FSS layers, (c) front and back side of the UWB antenna, and (d) composite structure.

\begin{tabular}{|c|c|c|c|c|c|}
\hline Parameter & $\begin{array}{c}\text { Value } \\
(\mathrm{mm})\end{array}$ & Parameter & $\begin{array}{c}\text { Value } \\
(\mathrm{mm})\end{array}$ & Parameter & $\begin{array}{c}\text { Value } \\
(\mathrm{mm})\end{array}$ \\
\hline$L$ & 27.5 & $j$ & 1.6 & $w$ & 5 \\
\hline$W$ & 16.5 & $e$ & 0.36 & $x$ & 6 \\
\hline$L g$ & 10 & $f$ & 0.45 & $y$ & 0.4 \\
\hline$a$ & 5.5 & $g$ & 0.3 & $m$ & 4 \\
\hline$b$ & 3.67 & $s$ & 10.6 & $n$ & 2.8 \\
\hline$c$ & 1.6 & $t$ & 10 & $o$ & 0.6 \\
\hline$i$ & 0.8 & $u$ & 8.6 & $p$ & 3.8 \\
\hline$k$ & 1.2 & $v$ & 1 & $q$ & 10.8 \\
\hline
\end{tabular}

Tab. 1. Optimal dimensions of the proposed antenna and FSS layers.

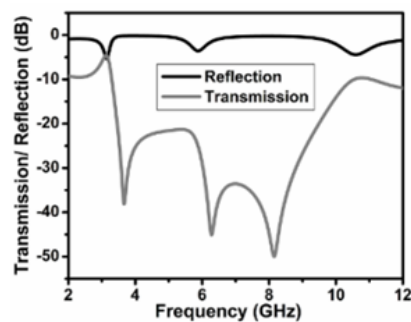

(a)

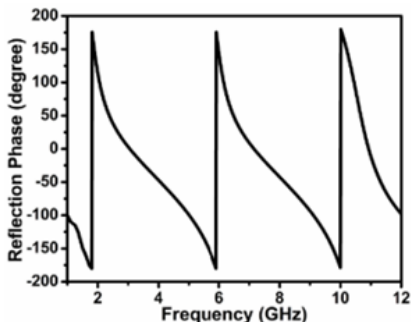

(b)
Fig. 5. Simulated transmission and reflection characteristics of the FSS: (a) Transmission and reflection coefficients. (b) Reflection phase. 
centric manner. The unit cell in the lower layer is formed with the combination of a Jerusalem cross shaped patch and a square loop shaped strip. The upper layer is chosen to achieve resonances near $4 \mathrm{GHz}$ and $8 \mathrm{GHz}$, whereas the lower layer resonates near $6 \mathrm{GHz}$ with a wide bandwidth. Accordingly the reflective FSS covers the UWB as can be observed in the reflection response of the FSS plotted in Fig. 5(a). Dimensions of the antenna and unit cells of the FSS layers are listed in Tab. 1. Transmission coefficient of the FSS is below $-10 \mathrm{~dB}$ over $3.3-10.5 \mathrm{GHz}$, leading to reflection close to $0 \mathrm{~dB}$ over the band. Reflection phase of the dual layer FSS, as shown in Fig. 5(b), exhibits that the phase is linear over the band and such response is useful in gain augmentation of the antenna. The upper layer and lower layer of FSS structure are fabricated on $1.6 \mathrm{~mm}$ thick FR4 epoxy substrate which has relative permittivity of 4.4 and loss tangent of 0.02 . The fabricated prototypes of FSS and antenna-FSS composite structure are shown in Fig. 4.

\subsection{Numerical Analysis for Notched Antenna- FSS Composite Structure}

A parametric study of the proposed antenna-FSS composite structure was carried out to determine the optimal spacing between the antenna and FSS. Figure 6(a) illustrates the simulated reflection coefficient $S_{11}$ whereas Figure 6(b) illustrates the simulated gain plot of the composite structure for varying distances between the antenna and FSS. The initial distance was chosen as $25 \mathrm{~mm}$ which is almost equal to $\lambda_{\mathrm{L}} / 4$ where $\lambda_{\mathrm{L}}$ corresponds to the lower band-edge frequency of UWB. A minor increment in the $-10 \mathrm{~dB}$ bandwidth can be seen with increasing the distance between the antenna and the FSS but the gain value in the pass band is reduced with such increment in the distance. $S_{11} \geq-10 \mathrm{~dB}$ is seen at $7.3 \mathrm{GHz}$ for the distance values of 25 and $26 \mathrm{~mm}$. Therefore $27 \mathrm{~mm}$ is selected as an optimal distance between the antenna and the FSS as in this distance the antenna-FSS composite structure provides a pass band gain variation of $4-9 \mathrm{dBi}$ in the impedance bandwidth.

\section{Characteristics of Antenna with FSS}

The composite structure is simulated using CST microwave studio suite [28], and the simulated results are later verified using experiment. The VSWR of antenna without FSS and with FSS are measured using R\&S ZVL13 VNA [30]. As can be seen in Fig. 7, the proposed antenna exhibits an impedance band from 1.75 to $10.3 \mathrm{GHz}$ with two notch bands at $2.2-3.9 \mathrm{GHz}$ and $5.1-6 \mathrm{GHz}$ as per the measurement whereas the simulated plot suggests an impedance band from 1.6 to $10.56 \mathrm{GHz}$ with dual frequency stop bands at $2.2-4 \mathrm{GHz}$ and $5-6.1 \mathrm{GHz}$. The antenna added with FSS provides almost similar VSWR profile which implies that the addition of FSS has a negligible effect on the VSWR response.

Simulated and measured co-polar radiation patterns of the antenna without FSS and with FSS in both E and H-

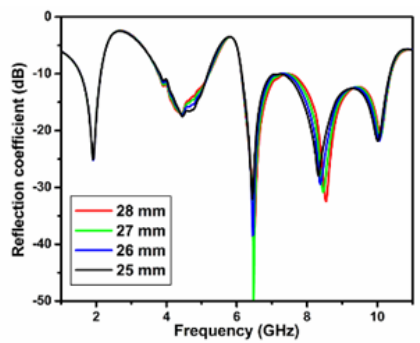

(a)

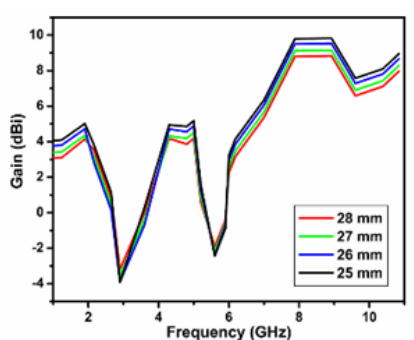

(b)
Fig. 6. Simulation plot of (a) Reflection coefficient $S_{11}$ and (b) gain variation with frequency, for different values of the distance between the antenna and FSS.

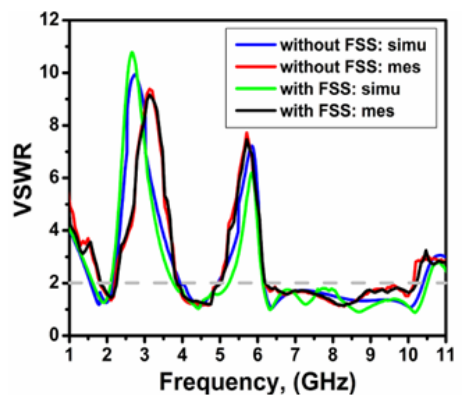

Fig. 7. Simulated and measured VSWR of the antenna with and without FSS.

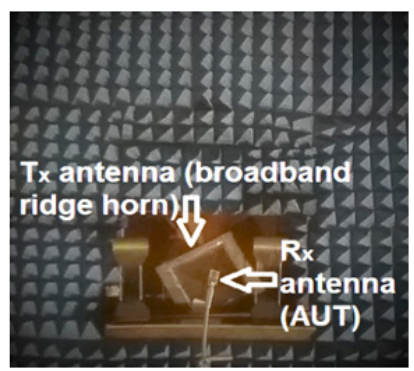

Fig. 8. Antenna radiation pattern measurement inside an anechoic chamber.

planes at 4.4, 6.5 and $8.5 \mathrm{GHz}$ are shown in Fig. 9. All the selected frequencies are in correspondence to the antenna resonances in the pass band, as can be observed in the $S_{11}$ profile. The dual notched antenna provides monopole like E-plane and non-directional H-plane pattern at all the frequencies. It is evident that with the addition of FSS, maximum antenna radiation in the broadside direction and reduction in the back lobe radiation is achieved. This attainment is crucial for application in GPR as GPR antennas primarily need to radiate in the broadside direction with a minimum back lobe radiation. Although the antenna offers an impedance band up-to $10.3 \mathrm{GHz}$ but the radiation patterns degrade from its usual shape for frequencies above $9 \mathrm{GHz}$. Variation between measured and simulated patterns become significant at upper frequencies mainly due to the selection of FR4 epoxy as substrate material. The cable losses and dielectric losses are important parameters to cause mismatch between simulated and measured antenna patterns. The antenna radiation pattern measurement set-up inside an anechoic chamber is shown in Fig. 8 .

Antenna gain is studied over frequency band following the gain transfer method [31]. The 'Fei Teng HA- 
08M18G-NF' standard gain ridge horn antennas are connected at both the transmitter and receiver ends at the very beginning. The received power $P_{\mathrm{s}}$ is measured accordingly. The receiver horn antenna is then replaced with the test antenna and the power received by the test antenna that is denoted as $P_{\mathrm{T}}$ is measured. The gain of the test antenna, represented as $G_{\mathrm{T}}$, is calculated using:

$$
G_{\mathrm{T}}(\mathrm{dB})=G_{\mathrm{S}}(\mathrm{dB})+10 \log _{10}\left(\frac{P_{\mathrm{T}}}{P_{\mathrm{S}}}\right) .
$$

Here $G_{\mathrm{s}}$ indicates the gain of the horn antenna. As shown in Fig. 10, the antenna without FSS has a gain variation between $2-4.5 \mathrm{dBi}$ in the operating band as per the measurement plot. The gain variation is enhanced to the range of 4.5-9 dBi with the addition of FSS layers. A gain augmentation of $5 \mathrm{dBi}$ is achieved at $8 \mathrm{GHz}$, whereas a large drop in the gain value can be observed in both the notch bands. Good agreement can be observed between the simulated and measured gain plots.

The radiation efficiency of the antenna is also studied experimentally with and without FSS using the modified Wheeler cap method as stated in [32]. Rectangular aluminum made boxes were created to shield the antenna radiation. $S_{11}$ of the antenna was measured using the R\&S ZVL-13 VNA with and without shielding. Dimensions of the

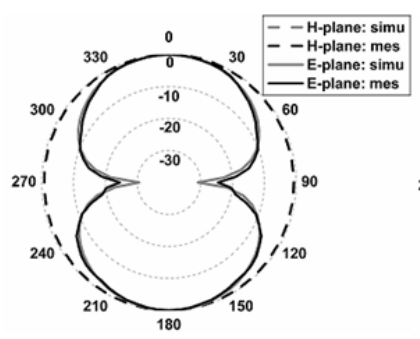

(a) Antenna without FSS at $4.4 \mathrm{GHz}$.

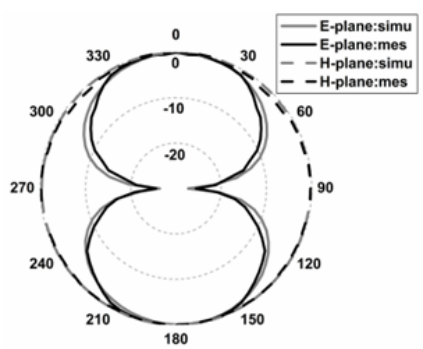

(c) Antenna without FSS at $6.5 \mathrm{GHz}$.

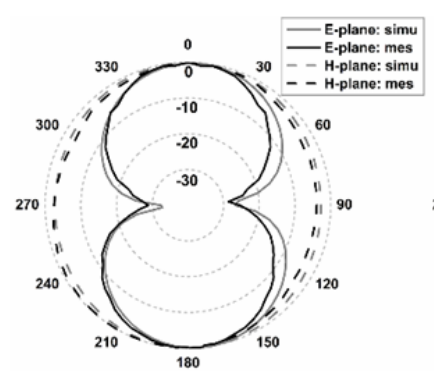

(e) Antenna without FSS at $8.5 \mathrm{GHz}$.

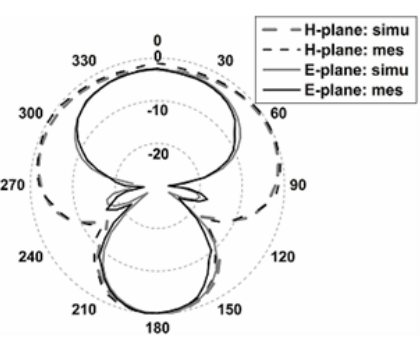

(b) Antenna with FSS at $4.4 \mathrm{GHz}$.

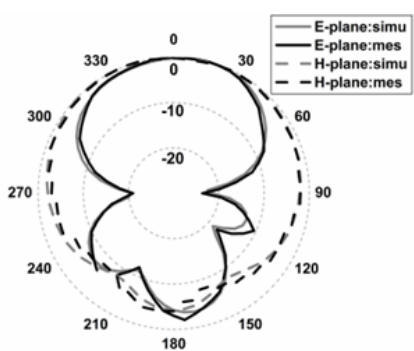

(d) Antenna with FSS at $6.5 \mathrm{GHz}$.

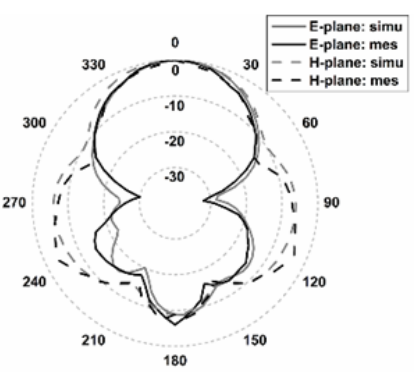

(f) Antenna with FSS at $8.5 \mathrm{GHz}$.
Fig. 9. Simulated and measured radiation pattern of the antenna with and without FSS at 4.4, 6.5 and $8.5 \mathrm{GHz}$ in the E and H-planes.

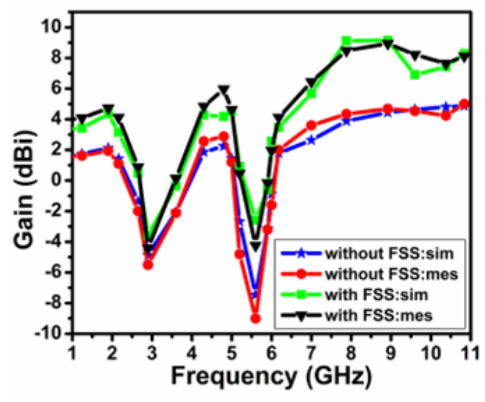

Fig. 10. Simulated and measured gain variation over frequency.

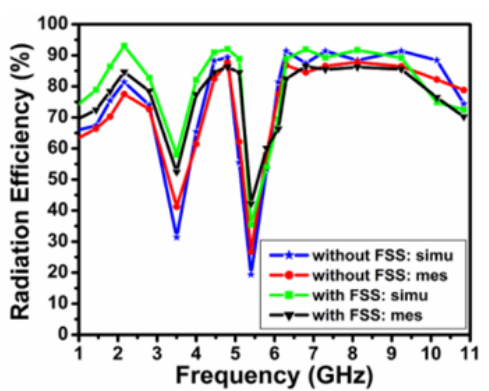

Fig. 11. Simulated and measured radiation efficiency over frequency.

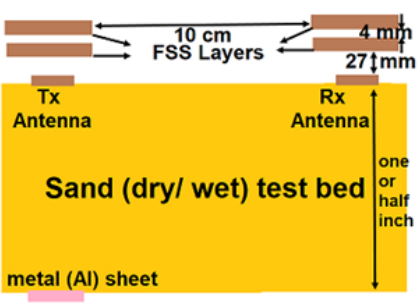

(a)

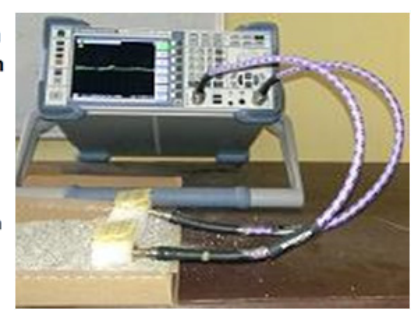

(b)
Fig. 12. Ground coupling GPR test set-up: (a) schematic, and (b) experimental set-up for one inch thick dry sand test bed.

boxes were chosen at transition from near to far field, such that it could reflect back all far field radiation without affecting the near-field energy storage. The radiation efficiency $\gamma$ can be measured following the equation:

$$
\gamma=\frac{S_{11 \mathrm{c}}^{2}-S_{11}^{2}}{1-S_{11}^{2}}
$$

Here $S_{11 c}$ represents reflection coefficient value when the antenna is shielded by the box and $S_{11}$ indicates the value without shielding. As plotted in Fig. 11, the antenna without FSS exhibits an average radiation efficiency of more than $80 \%$ in the pass band. The efficiency increases about $2 \%$ after the addition of FSS reflectors. Significant reduction in efficiency can be observed in the frequency notch bands. Decent matching can be seen between the simulated and measurement plots.

The notched antenna-FSS composite structure is experimentally studied in close vicinity of a sand test bed. The experimental schematic is shown in Fig. 12(a) and the picture of experimental set up with one inch thick dry sand test bed is shown in Fig. 12(b). As shown in Fig. 12, two similar antenna prototypes, backed by FSS layers are 
placed at a distance of $10 \mathrm{~cm}$, considering one as transmitting and another as a receiving unit. Both the antenna-FSS prototypes are connected to the dual ports of VNA. A thin aluminum sheet is buried at the bottom of the test bed. The test bed is filled with either dry or wet sand. The sheet depth is chosen as half inch in one set of measurement and one inch in another set of measurement for both types of sand.

As plotted in Fig. 13, the antenna operating bandwidth with dual notches remains unaffected in this ground coupling GPR test. A noticeable degradation in VSWR mainly at high frequency can be observed for wet sand test bed. Attenuation of transmitted waves inside sand increases at higher frequencies due to the presence of water molecules in the sand.

As plotted in Fig. 14, magnitude response of the antenna transfer function $S_{21}$ is found almost constant around $-20 \mathrm{~dB}$ in the frequency band from $3.5-9.3 \mathrm{GHz}$ except the notch band around $5 \mathrm{GHz}$ for dry sand. However

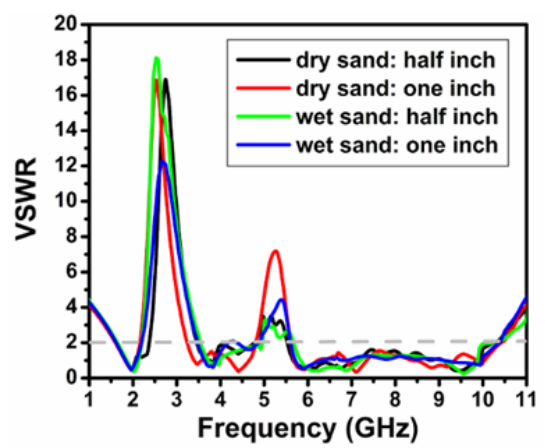

Fig. 13. Measured VSWR for dry and wet sand made test bed.

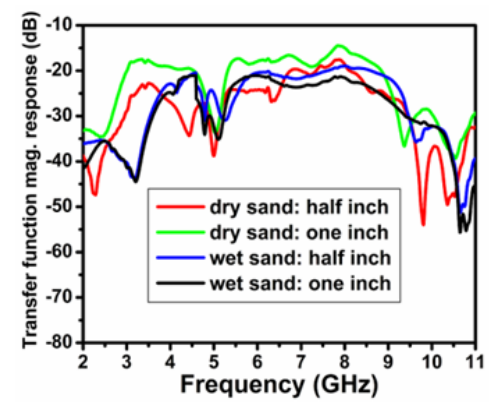

Fig. 14. Magnitude of antenna transfer function $S_{21}$ in GPR test.

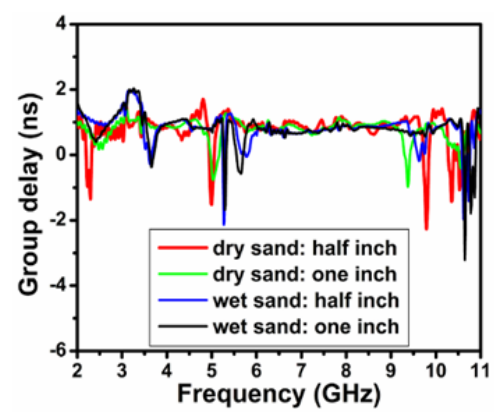

Fig. 15. Comparative study of group delay of antenna-FSS in GPR test. consistency in $S_{21}$ around $-25 \mathrm{~dB}$ can be observed in the 3.8-9.5 GHz frequency band for wet sand test bed. Significant reduction in $S_{21}$ value can be seen at $5-5.8 \mathrm{GHz}$ band due to the existence of frequency stop band. The group delay variation with frequency is also measured from $S_{21}$ using VNA and it is observed that in the pass band of the the antenna it remains almost non-varying as evident in Fig. 15. Major degradation in group delay response can be seen in the notch bands. Almost flat group delay response in the operating band indicates linear phase response which makes the antenna less dispersive and suitable for GPR applications.

\section{Conclusions}

A high gain, less dispersive and compact UWB antenna incorporated with a dual layer reflective FSS is proposed. The antenna provides maximum gain of about $9 \mathrm{dBi}$ in the impedance band of $1.75-10.3 \mathrm{GHz}$, almost covering the unlicensed UWB band of $3.1-10.6 \mathrm{GHz}$ with band rejection in the frequency bands of $2.2-3.9 \mathrm{GHz}$ and 5.1-6 GHz. The antenna gain is enhanced in the broadside direction by the FSS reflectors over the operating band. However the gain is reduced significantly in the notch bands. The antenna response is studied for ground coupling GPR applications. Stable and linear transfer function response and flat group delay response are obtained in the antenna pass band which confirm low dispersive nature of the proposed UWB antenna and thus ensure its working capability as a GPR antenna.

\section{References}

[1] DANIELS, D. J. Ground Penetrating Radar. 2nd ed. London, (UK): IET Press, 2004. ISBN: 9780863413605

[2] JOL, H. M. (Ed.). Ground Penetrating Radar Theory and Applications. Elsevier, 2008. ISBN: 9780444533487

[3] FEDERAL COMMUNICATIONS COMMISSION, Washington, D.C. 20554. First Report and Order. 118 pages. [Online] Cited 2001-10-16. Available at: https://transition.fcc.gov/Bureaus/Engineering_Technology/Orders /2002/fcc02048.pdf

[4] HONG, S., SHIN, J., PARK, H., et al. Analysis of the band stop techniques for ultrawideband antenna. Microwave and Optical Technology Letters, 2007, vol. 49, no. 5, p. 1058-1062. DOI: $10.1002 /$ mop. 22363

[5] LEE, W. S., KIM, D. Z., KIM, K. J., et al. Wideband planar monopole antennas with dual band-notched characteristics. IEEE Transactions on Microwave Theory and Techniques, 2006, vol. 54, no. 6, p. 2800-2806. DOI: 10.1109/TMTT.2006.874895

[6] FARROKH-HESHMAT, N., NOURINIA, J., GHOBADI, C. Band-notched ultra-wideband printed open-slot antenna using variable on-ground slits. Electronics Letters, 2009, vol. 45, no. 21, p. 1060-1061. DOI: 10.1049/el.2009.1887

[7] MA, T. G., HUA, R. C., CHOU, C. F. Design of a multiresonator loaded band-rejected ultrawideband planar monopole antenna with controllable notched bandwidth. IEEE Transactions on Antennas and Propagation, 2008, vol. 56, no. 9, p. 2875-2883. DOI: 10.1109/TAP.2008.928778 
[8] SIDDIQUI, J. Y., SAHA, C., ANTAR, Y. M. Compact dual-SRRloaded UWB monopole antenna with dual frequency and wideband notch characteristics. IEEE Antennas and Wireless Propagation Letters, 2015, vol. 14, p. 100-103. DOI: 10.1109/LAWP.2014.2356135

[9] KUNDU, S., JANA, S. K. Leaf-shaped CPW-fed UWB antenna with triple notch bands for ground penetrating radar applications. Microwave and Optical Technology Letters, 2018, vol. 60, no. 4, p. $930-936$. DOI: $10.1002 / \mathrm{mop} .31075$

[10] SARKAR, D., SRIVASTAVA, K. V., SAURAV, K. A compact microstrip-fed triple band-notched UWB monopole antenna. IEEE Antennas and Wireless Propagation Letters, 2014, vol. 13, p. 396-399. DOI: 10.1109/LAWP.2014.2306812

[11] LIANG, J., CHIAU, C. C., CHEN, X. D., et al. Study of a printed circular disk monopole antenna for UWB systems. IEEE Transactions on Antennas and Propagation, 2005, vol. 53, no. 11, p. $3500-3504$. DOI: $10.1109 /$ TAP.2005.858598

[12] SRIFI, M. N., PODILCHAK, S. K., ESSAAIDI, M., et al. Compact disc monopole antennas for current and future ultrawideband (UWB) applications. IEEE Transactions on Antennas and Propagation, 2011, vol. 59, no. 12, p. 4470-4480. DOI: $10.1109 /$ TAP.2011.2165503

[13] SIDDIQUI, J. Y., SAHA, C., ANTAR, Y. M. Compact SRR loaded UWB circular monopole antenna with frequency notch characteristics. IEEE Transactions on Antennas and Propagation, 2014, vol. 62, no. 8, p. 4015-4020. DOI: 10.1109/TAP.2014.2327124

[14] LUKEŠ, Z., LÁČ́́K, J., RAIDA, Z. Modeling and optimizing antennas for rotational spectroscopy applications. Radioengineering, 2006, vol. 15, no. 4, p. 91-95. ISSN: 12102512

[15] LIU, H., ZHAO, J., SATO, M. A hybrid dual-polarization GPR system for detection of linear objects. IEEE Antennas and Wireless Propagation Letters, 2015, vol. 14, p. 317-320. DOI: 10.1109/LAWP.2014.2363826

[16] SCHNEIDER, J., MRNKA, M., GAMEC, J., et al. Vivaldi antenna for RF energy harvesting. Radioengineering, 2016, vol. 25, no. 4, p. 666-671. DOI: 10.13164/re.2016.0666

[17] LESTARI, A. A., YAROVOY, A. G., LIGTHART, L. P. RCloaded bow-tie antenna for improved pulse radiation. IEEE Transactions on Antennas and Propagation, 2004, vol. 52, no. 10, p. 2555-2563. DOI: 10.1109/TAP.2004.834444

[18] ChATTERJEE, A., PARUI, S. K. Gain enhancement of a wideslot antenna using dual-layer, bandstop frequency selective surface as a substrate. Microwave and Optical Technology Letters, 2015, vol. 57, no. 9, p. 2016-2020. DOI: 10.1002/mop.29250

[19] PIRHADI, A., BAHRAMI, H., NASRI, J. Wideband high directive aperture coupled microstrip antenna design by using a FSS superstrate layer. IEEE Transactions on Antennas and Propagation, 2012, vol. 60 , no. 4, p. 2101-2106. DOI: 10.1109/TAP.2012.2186230

[20] CHATterJeE, A., PARUI, S. K. Performance enhancement of a dual-band monopole antenna by using a frequency-selective surface-based corner reflector. IEEE Transactions on Antennas and Propagation, 2016, vol. 64, no. 6, p. 2165-2171. DOI: 10.1109/TAP.2016.2552543

[21] CHEN, H.-Y., TAO, Y. Performance improvement of a U-slot patch antenna using a dual-band frequency selective surface with modified Jerusalem cross elements. IEEE Transactions on Antennas and Propagation, 2011, vol. 59, no. 9, p. 3482-3486. DOI: 10.1109/TAP.2011.2161440

[22] FOROOZESH, A., SHAFAI, L. Investigation into the effects of the patch-type FSS superstrate on the high-gain cavity resonance antenna design. IEEE Transactions on Antennas and Propagation, 2010, vol. 58, no. 2 , p. 258-270. DOI: 10.1109/TAP.2009.2037702
[23] ChATTERJEE, A., PARUI, S. K. Frequency-dependent directive radiation of monopole-dielectric resonator antenna using a conformal frequency selective surface. IEEE Transactions on Antennas and Propagation, 2017, vol. 65, no. 5, p. 2233-2239. DOI: 10.1109/TAP.2017.2677914

[24] AHMED, A., ZHANG, Y., BURNS, D., et al. Design of UWB antenna for air-coupled impulse ground-penetrating radar. IEEE Geoscience and Remote Sensing Letters, 2016, vol. 13, no. 1, p. 92-96. DOI: 10.1109/LGRS.2015.2498404

[25] SHAO, J., FANG, G., FAN, J., et al. TEM horn antenna loaded with absorbing material for GPR applications. IEEE Antennas and Wireless Propagation Letters, 2014, vol. 13, p. 523-527. DOI: 10.1109/LAWP.2014.2311436

[26] KUNDU, S., JANA, S. K. A compact umbrella shaped UWB antenna for ground coupling GPR applications. Microwave and Optical Technology Letters, 2017, vol. 60, no. 1, p. 146-151. DOI: 10.1002/mop.30928

[27] KUNDU, S., JANA, S. K. A leaf-shaped CPW-fed UWB antenna for GPR applications. Microwave and Optical Technology Letters, 2018 , vol. 60 , no. 4 , p. $941-945$. DOI: $10.1002 /$ mop. 31089

[28] COMPUTER SIMULATION TECHNOLOGY (CST), CST Microwave Studio. [Online] Cited 2015-10-26. Available at: https://www.cst.com/Products/CSTMWS. 2015

[29] CHO, Y. J., KIM, K. H., CHOI, D. H., et al. A miniature UWB planar monopole antenna with 5-GHz band-rejection filter and the time-domain characteristics. IEEE Transactions on Antennas and Propagation, 2006, vol. 54, no. 5, p. 1453-1460. DOI: 10.1109/TAP.2006.874354

[30] https://www.rohde-schwarz.com/us/product/zvl13productstartpage_63493-10575.html

[31] BALANIS C. A. Antenna Theory: Analysis and Design. $3^{\text {rd }}$ ed. Hoboken: Wiley, 2005. ISBN: 978-0471667827

[32] MURAMOTO, M., ISHII, N., ITOH, K. Radiation efficiency measurement of a small antenna using the Wheeler method. Electronics and Communication in Japan, 1996, vol. 79, no. 6, p. $93-100$. DOI: $10.1002 /$ ecja.4410790610

\section{About the Authors...}

Surajit KUNDU (1985) received his B.Tech. degree in Electronics and Communication Engineering from the Academy of Technology, West Bengal University of Technology, India in 2009 and M.Tech. degree from the Indian Institute of Technology Kharagpur in 2012. Presently he is pursuing Ph.D. degree (thesis submitted) from the National Institute of Technology Sikkim, India. His research interest includes antenna design, ultra-wideband communication and ground penetrating radar. He has served at the Dept. of ECE, Supreme Knowledge Foundation Group of Institutions as an Assistant Professor in the year of 2012 and also worked in the Dept. of ECE, UIT, University of Burdwan in the year of 2013. Since 2014, he is working as an Assistant Professor in the Dept. of Electronics and Communication Engineering, National Institute of Technology Sikkim, South Sikkim, India. He has published more than 15 papers in referred journals and conference proceedings.

Ayan CHATTERJEE (1988) received his B.Tech. degree in Electronics and Communication Engineering from the West Bengal University of Technology, India in the year 2010. He did M.Tech. in Communication Engineering from University of Kalyani, India in 2012. From 2012 to 2013, 
he worked as an Assistant Professor in the Supreme Knowledge Foundation Group of Institutions, West Bengal. He has completed his Ph.D. in Microwave Engineering in the Dept. of Electronics and Tele-Communication Engineering, Indian Institute of Engineering Science \& Technology, Shibpur. Since 2018, he is associated with the Dept. of Electronics and Communication Engineering in Nation Institute of Technology Sikkim. He was awarded Senior Research Fellowship by CSIR, Govt. of India in 2014. His research interests include Frequency Selective Surfaces, Artificial Magnetic Conductors, slot antennas, and other wideband antennas. He has published more than 20 papers in referred journals and conference proceedings.

Sanjay Kumar JANA (1979) received his M.Tech. degree from Jadavpur University in 2007 and Ph.D. degree from IIT Kharagpur in 2016. Presently he is working as an Assistant Professor in the Dept. of ECE, NIT Sikkim. His research interests are mainly in mixed signal \& RFIC design and growth by MBE \& MOCVD and characterization by HRXRD, ECV, and Hall\&PL. He has published more than 30 papers in referred journals and conference proceedings.

Susanta Kumar PARUI (1965) received his B.Sc. degree in Physics and B.Tech. degree in Radio Physics and Electronics from the University of Calcutta in the year 1987 and 1990, respectively. He did M.E. and Ph.D in Microwave Engineering from Bengal Engineering and Science University (presently known as Indian Institute of Engineering Science \& Technology), Shibpur, India. From 1993 to 2000, he worked as an Instrument Engineer in Process control Industries. Since 2000, he is associated with the Dept. of Electronics and Tele-Communication Engineering in the Indian Institute of Engineering Science \& Technology, Shibpur and presently holds the post of Associate Professor. He was awarded post-doctoral fellowship from the Royal Academy of Engineering, U.K in the year 2009. His current research interests include planar circuits, antennas, SIW, DGS, EBG and metamaterials. He has published more than 50 contributory papers in referred journals and international conference proceedings. 